\title{
Aspects Regarding Movila Verde-Independenta Water Supply Duct Protection from Water Hammer
}

\author{
Claudiu Nițescu and Anca Constantin
}

\begin{abstract}
In the context of sustainable development effort, the water supply systems in the rural area of Constanta County should be optimally designed, so that their safe, efficient operation is assured. The results obtained by numerical simulation showed that Movila Verde -Independenta water supply duct might be subject of cavitation occurrence during hydraulic shock. Further investigations showed that the duct is adequately protected by a relatively short closing law of the check valve and three air valves mounted in the nodes where cavitation might occur. Minimal pressure increases from $\mathbf{- 1 0} \mathbf{m w c}$ to $\mathbf{- 0 . 6} \mathbf{m w c}$ because of these protection measures. Furthermore, the slight increase of maximal pressure does not require additional protection devices.
\end{abstract}

Keywords - hydraulic shock, sustainability, water supply systems

\section{INTRODUCTION}

Since early 1990s when it was proposed, the integrated management of water and energy resources has been developed especially with respect to water supply systems aiming to simultaneously solve stringent problems like increasing energy prices, water supply quality and water scarcity. The concept was developed as an operational optimization framework [1] for improving the efficiency of water facilities and it became part of the larger concept of sustainable development. Among the goals stated by the ambitious plan for Sustainable Development released in 2015 [2], the Goal 6: Clean Water and Sanitation, sets the achievement of universal and equitable access to safe and affordable drinking water for all, by 2030. An important increase in water-use efficiency and a sustainable freshwater water supply of urban and rural regions can only be created on the basis of a sound water infrastructure, in the framework of a safe operation of the water systems. A major problem that puts into jeopardy the integrity and the efficient of the water pipelines is the water hammer phenomenon. Considerable efforts have been made by scholars to understand the mechanisms of water hammer phenomenon and to create methods and devices for duct protection from pressure picks that accompany this phenomenon. A reference work of Streeter [3] brings together different methods for transient flow analysis and develops the method of characteristics as a basis for future software oriented on water hammer. Among numerous scientific publications dedicated to this phenomenon, we may mention a comprehensive study on hydraulic shock in hydropower plants and pumping stations developed by Popescu at al. [4]. These works offer the possibility to identify the extreme pressure values that occur during water hammer and the most vulnerable cross sections of a duct. At present, scholars and practitioners benefit from different software products, oriented on water hammer protection. 
Numerical simulation helps the specialists to decide among different technical alternatives regarding water hammer protection of a duct, in the early phase of engineering design.

The study presented in this work aims to identify, by numerical simulation, the optimal devices and operation method regarding the water hammer protection of the water supply duct that conveys water in the Independenta village system, in Constanta County. The protection alternatives were technically and economically analysed prior to recommend a specific one.

\section{METHODOLOGY}

Independenta is a village in Southern Constanta County, supplied by the water facility in the neighbouring village, Movila Verde. The source is underground water, pumped by a pumping station placed in Movila Verde and conveyed to Independenta by a HDPP made duct, of $200 \mathrm{~mm}$ in diameter and $6508 \mathrm{~m}$ in length. The pumping station works at a capacity of $41,76 \mathrm{~m}^{3} / \mathrm{s}$ at a head of $28 \mathrm{~m}$. The maximal pressure the duct resists at is 10 bar. The duct is buried, following the terrain profile, so the duct longitudinal profile is characterised by steer slopes that often change. The layout of the duct is represented in Figure1.

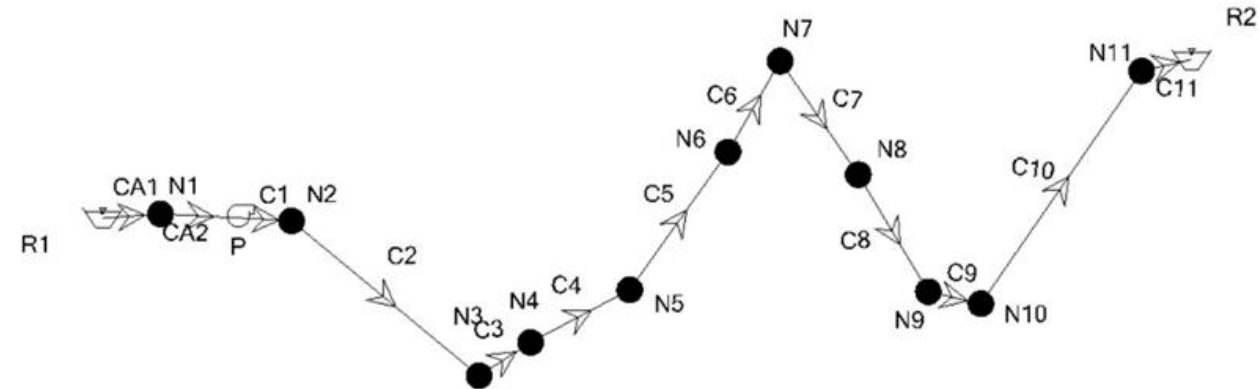

Fig. 1. Movila Verde-Independenta water supply duct

Table 1 gives the elevation in the main nodes of this duct and the cumulative distance from the pump for each node.

Table. 1. Elevation and cumulative distance from the pump for the nodes in Figure 1

\begin{tabular}{|c|c|c||c|c|c|}
\hline Node & $\begin{array}{c}\text { Elevation, } \\
{[\mathbf{m}]}\end{array}$ & $\begin{array}{c}\text { Cumulative } \\
\text { distance, [m] }\end{array}$ & Node & $\begin{array}{c}\text { Elevation, } \\
{[\mathbf{m}]}\end{array}$ & $\begin{array}{c}\text { Cumulative } \\
\text { distance, [m] }\end{array}$ \\
\hline P & 131.88 & 0 & N7 & 150.98 & 4058 \\
\hline N3 & 92.43 & 1111 & N8 & 140.79 & 4973 \\
\hline N4 & 104.1 & 1279 & N9 & 114.29 & 5769 \\
\hline N5 & 126.42 & 2067 & N10 & 113.55 & 5920 \\
\hline N6 & 138.98 & 3447 & N11 & 147.66 & 6490 \\
\hline & & & R2 & 147.89 & 6508 \\
\hline
\end{tabular}

Taking into account the profile of the terrain a hydraulic analysis is necessary, in order to investigate the pressure variation during the occurrence of the water hammer 
phenomenon. It was considered the most dangerous case that of a sudden electric power shut off, when all the pumps are being operating.

The non-commercial software used for this analysis is conceived on the base of the method of characteristics for solving the water hammer equations and takes into account the compressibility of both water and the duct. The water flow is one-dimensional, and the head loss formula used in steady movement are considered either for transient movement. A brief description of the programme is given in previous a work [5].

The supply duct was divided into 10 sections, resulting 11 calculation nodes, as may be seen in Fig.1. The boundary conditions [4] were imposed according to the pump, reservoir and specific devices mounted in these nodes along duct.

The numerical simulation was conducted step by step, starting with the case the duct is unprotected and continuing with different devices added in the vulnerable nodes, considering the most affordable equipment from economic viewpoint. The simulation scenarios presented further are:

a. The duct is unprotected.

b. The duct is protected by two air valves and a closing law of the check valve.

c. The duct is protected by two air valves and a closing law of the check valve.

\section{RESULTS AND DISCUSSION}

The simulation of water hammer occurrence in the first case, where the duct is unprotected, highlighted that the maximal pressure values are not a threaten to the duct, but cavitation is. As it may be seen in Table 2, maximal pressure is registered in N3, the node with the lowest elevation, and it is of only $76,99 \mathrm{mwc}$, bellow the nominal pressure endured by the duct. Cavitation occurs in node N7 and in the last calculation node.

Table. 2 Field of extreme pressure values in nodes, as the duct is unprotected

\begin{tabular}{|c|c|c|}
\hline Node & $\begin{array}{c}\text { Maximal } \\
\text { pressure } \\
\text { values (mwc) }\end{array}$ & $\begin{array}{c}\text { Minimal } \\
\text { pressure values } \\
\text { (mwc) }\end{array}$ \\
\hline P & 47,93 & 7,54 \\
\hline N2 & 42,63 & 7,54 \\
\hline N3 & 76,99 & 36,82 \\
\hline N4 & 65,46 & 25,18 \\
\hline N6 & 27,32 & 6,83 \\
\hline N7 & 20,09 & -10 \\
\hline N9 & 50,99 & 19,47 \\
\hline N10 & 51,8 & 20,09 \\
\hline N11 & 14,58 & -10 \\
\hline
\end{tabular}

For a better understanding of the pressure variation, the pressure time series are given in Figure 2, for the nodes P (pump) and N7 and in Figure 3 for N2 and N6 that means the cross section where the extreme pressure values were obtained.

In the case the duct has no protective devices, the minimal pressure at the pump node reaches $-6.95 \mathrm{mwc}$ and the negative pressure spans downstream. Cavitation, $-10 \mathrm{mwac}$, is noticed at node $\mathrm{N} 7$ and it lasts for $31 \mathrm{~s}$. It either occurs a few times in the analysed period, along the last part of the duct.

The results show that a protection method should be used. 


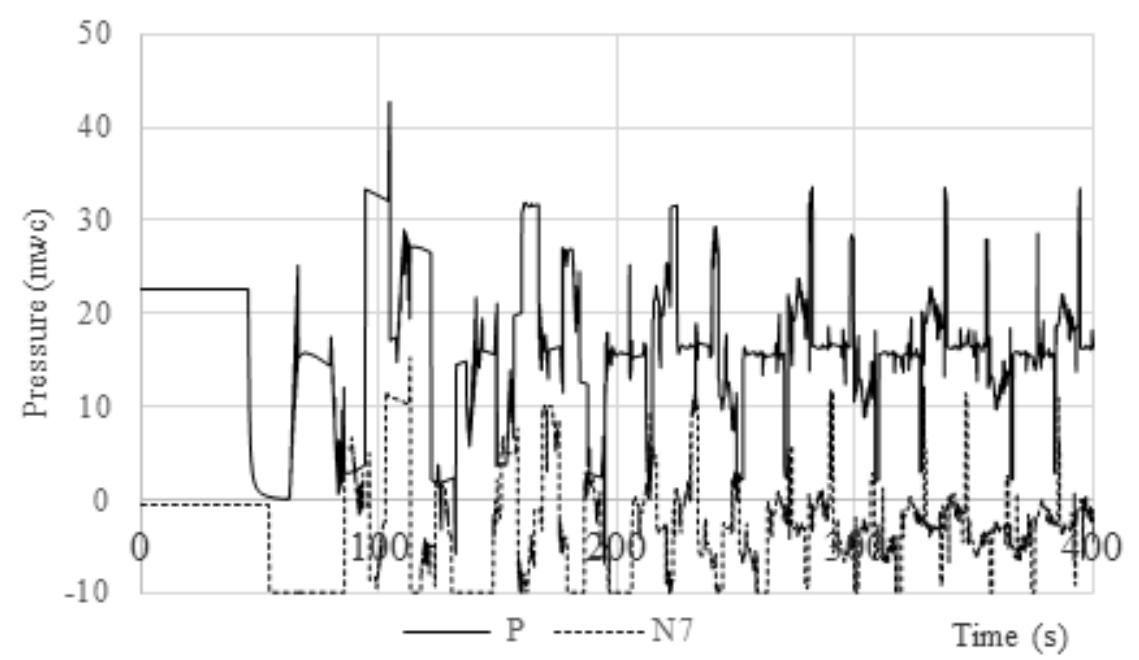

Fig. 2. Pressure variation in nodes $P($ pump) and $N 7$ of the unprotected duct

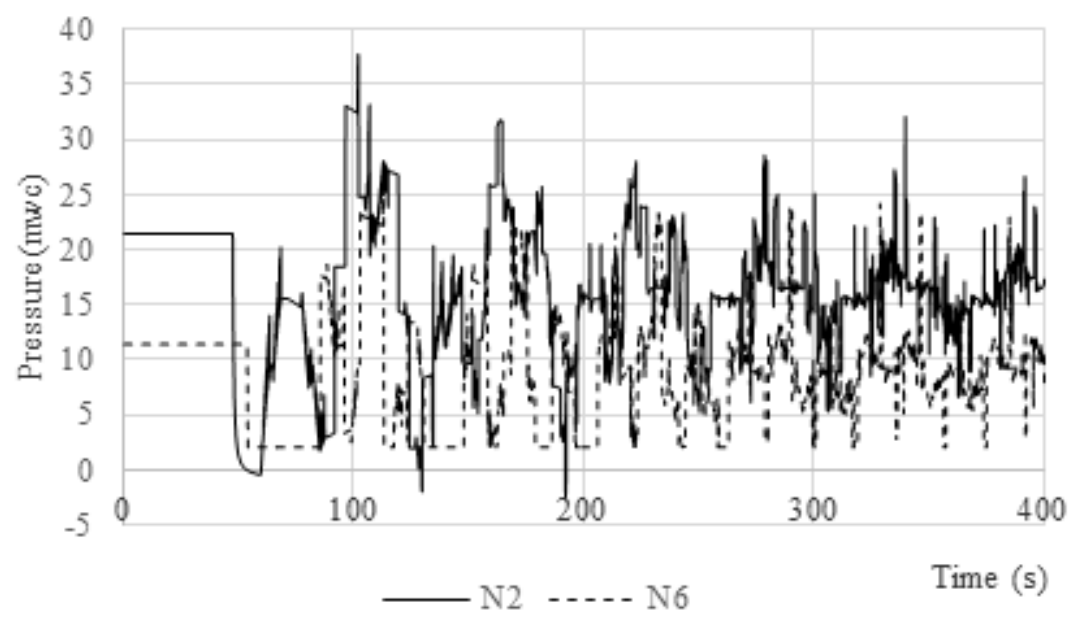

Fig. 3. Pressure variation in nodes $\mathrm{N} 2$ and N6, in the unprotected duct

The first adopted measure was a $45 \mathrm{~s}$ closing time for the check valve on the duct. Additionally, two air valves were mounted in nodes N2, close to the pump, and respectively $\mathrm{N} 7$, considering air valves as an affordable and effective device.

Better results were obtained in this case, as it may be noticed in Fig. 4. Cavitation disappears in nodes N2 and N7. Minimal pressure in N7 is $-0.61 \mathrm{mwc}$, a harmless value. Besides, maximal pressure decreases by $10 \mathrm{mwc}$ and respectively $20 \mathrm{mwc}$.

In node $\mathrm{N} 6$, at $7 \mathrm{~s}$ after the check valve closes, the pressure drops at $-6.6 \mathrm{mwc}$, therefore an additional air valve was needed in the intermediate node N6. 


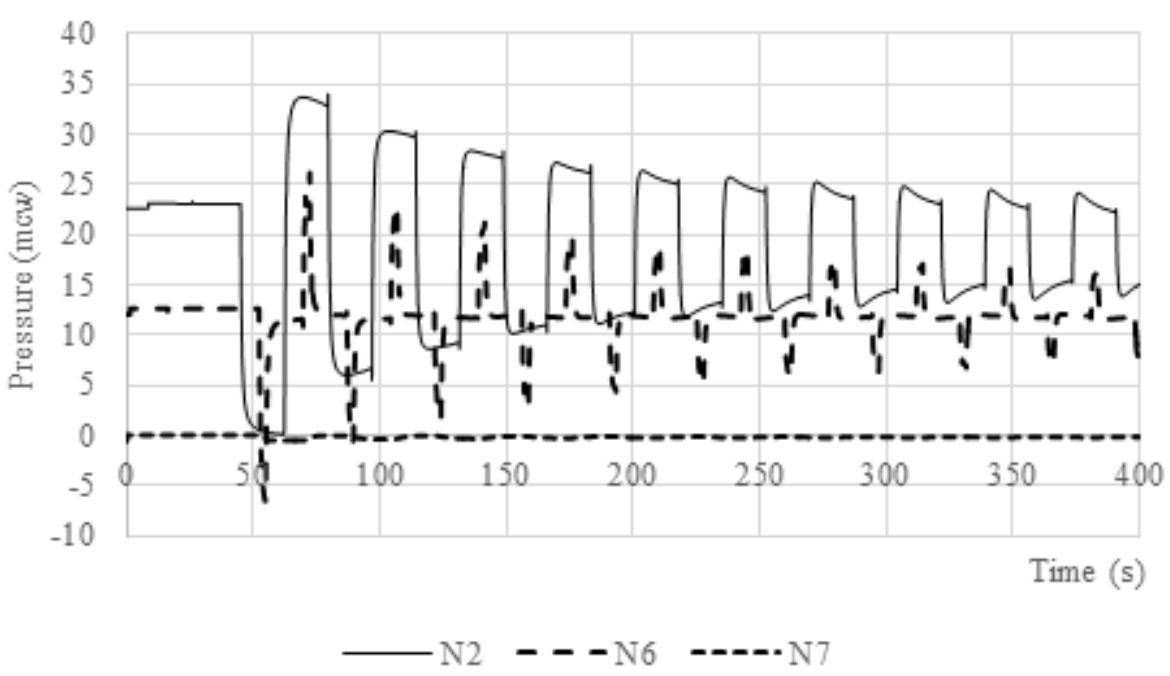

Fig. 4. Pressure variation at nodes N2, N6 and N7, in the case the duct is protected by two air valves

The third protection case, that considers three air valves in nodes N2, N6 and N7, eliminates the cavitation along the duct. Minimal pressure at node N6 increases at -0.6 mwc.

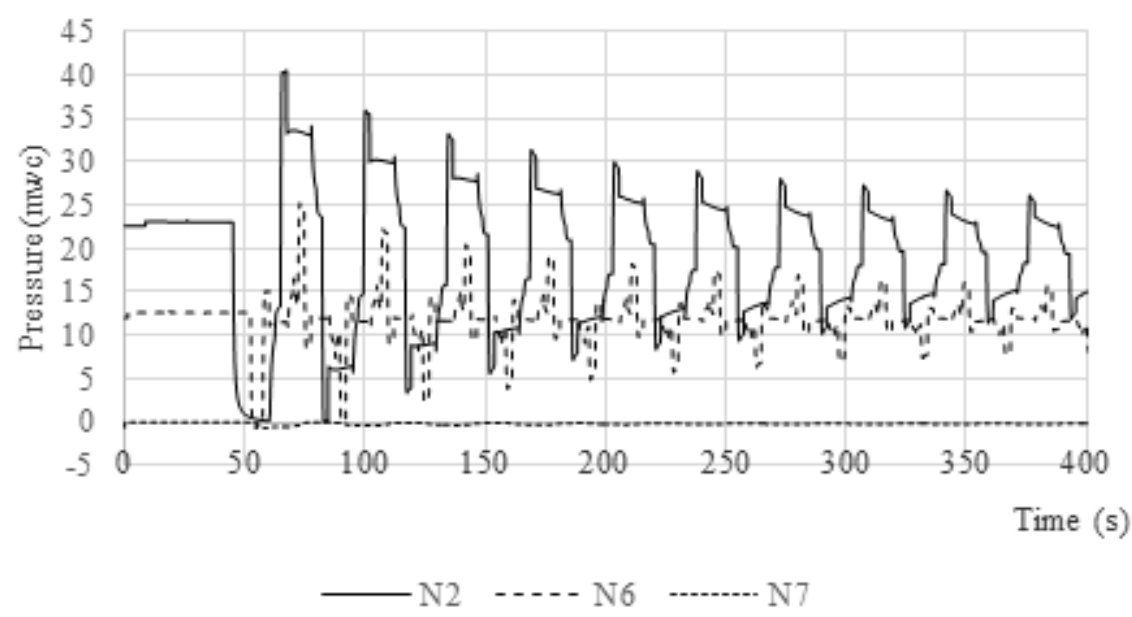

Fig. 5. Pressure variation in nodes N2, N6 and N7, in the case the duct is protected by three air valves

Maximal pressure at node $\mathrm{P}$ increases with $6 \mathrm{mwc}$. On the descendent section of the duct downstream the pump, maximal pressure increases as well, and in node N3 it increases with $3 \mathrm{mwc}$, but these values do not put the duct in danger. The increase of maximal pressure in nodes with low elevation do not require protection means. 
The time series for pressure variation in the nodes equipped with air valves are represented in Figure 5.

This combined method of protection is considered optimal from technical viewpoint and implies lower costs than other methods based on air chamber for example.

\section{CONCLUSIONS}

The numerical simulation of pressure variation was performed on a water supply duct, part of the water supply system in Constanta County rural area. The difficulty of this long duct consists of steep, variable slopes, with two nodes with the elevation lower than the water supply reservoir and one node higher than the elevation of the discharge reservoir.

Numerical simulation led to a whole image of the pressure variation along the duct, highlighting the danger of cavitation occurrence over a long section, during more than $31 \mathrm{~s}$. New simulation in different scenarios of water hammer protection methods, allowed the selection of the optimal one that involves low costs of investment and operation.

The correct identification of the vulnerable cross sections of the duct permitted an appropriate placement of the protection devices. The results showed the duct is adequately protected by a relatively short closing law of the check valve and three air valves mounted in the nodes where cavitation might occur. Minimal pressure increases from -10 mwc to $0.6 \mathrm{mwc}$ as a consequence of these protection measures. Furthermore, the slight increase of maximal pressure does not require additional protection devices.

\section{REFERENCES}

[1] C. Cherchi, M. Badruzzaman, J. Oppenheimer, C. M. Bros and J. Jacangelo (2015) Energy and water quality management systems for water utility's operations: A review, Journal of Environmental Management, Volume 153, pp 108-120

[2] United Nations, (2015) Transforming our world: the 2030 Agenda for Sustainable Development, Goal 6: Ensure availability and sustainable management of water and sanitation for all, https://sdgs.un.org/2030agenda

[3] V.L. Streeter, B. E. Wylie, (1984) Hydraulic transients, McGraw - Hill Book Company, New York

[4] M. Popescu, D.I. Arsenie, and P. Vlase, (2004) Applied Hydraulic Transients for Hydropower Plants and Pumping Stations, Balkema Publishers, Lisse, Abington, Tokyo

[5] A. Constantin, C. Ș. Nițescu, Study into water hammer protection of a water supply duct in Movila Verde, Constanta. Construction of optimized energy potential. 2020 (2):39-44. doi:10.17512/bozpe.2020.2.05, http://www.bozpe.bud.pcz.pl/Study-into-water-hammerprotection-of-a-water-supply-duct-nin-Movila-Verde-Constanta,133216,0,2.html

\section{Note:}

Claudiu Ștefan Nițescu - Ovidius University of Constanta, Bd. Mamaia nr. 124, 900356-Constanta, Romania (corresponding author to provide tel: +40-0724056939; e-mail: claudiu.nitescu@univ-ovidius.ro) Anca Constantin - Ovidius University of Constanta, Bd. Mamaia nr. 124, 900356-Constanta, Romania (email: aconstantina@univ-ovidius.ro) 